Dhaka Univ. J. Biol. Sci. 25(2): 113-121, 2016 (July)

\title{
DEPRESSION OF MARRIED WOMEN: EXPLORING THE ROLE OF EMPLOYMENT STATUS, MARITAL SATISFACTION AND PSYCHOLOGICAL WELL-BEING
}

\author{
Md. Azharul Islam* ${ }^{*}$ Sayeda Amina Efat ${ }^{1}$, Ayesha Binte Yousuf $^{1}$ \\ AND SHAHEEN ISLAM \\ Department of Educational and Counselling Psychology, \\ University of Dhaka, Dhaka-1000 Bangladesh
}

Key words: Depression, Marital satisfaction, Psychological well-being, Women

\begin{abstract}
This study was carried out to explore the level of depression among married women. Additionally, the role of employment status, academic qualification, marital satisfaction and psychological well-being on depression was examined. Depression, marital satisfaction and psychological well-being of 200 married women were assessed. Results showed $15 \%$ of the study participants scored above the cut-off point of depression and are at the risk of depression. Employment and academic status, marital satisfaction and psychological wellbeing (GHQ-28) jointly accounted for $56.2 \%$ variability in the depression with psychological well-being $(\beta=0.515, \mathrm{p}<0.001)$ and marital satisfaction $(\beta=-0.276$, $\mathrm{p}<0.001)$ appeared as the most influential predictors. Lower education and unemployment also associated with the higher level of depression. The model indicated if a married woman with poorer psychological well-being, lower marital satisfaction and lower educational qualification is unemployed, she is more likely to be diagnosed as depressed. Implications and future direction are discussed.
\end{abstract}

\section{Introduction}

Depression is a condition in which a person feels discouraged, sad, hopeless, unmotivated, or disinterested in life in general. According to the fifth edition of the Diagnostic and Statistical Manual of Mental Disorders (DSM-5)(1), 'five (or more) of the described symptoms have to be present during the same 2-week period and represent a change from previous functioning; at least one of the symptoms is either depressed mood or loss of interest or pleasure'. The symptoms cause clinically significant distress or impairment in social, occupational or other important areas of functioning.

Depression is one of the leading causes of the global burden of diseases and accounted for people's poorer quality of life globally. WHO estimated 350 million people around the globe is affected in depression ${ }^{(2)}$. A recent survey conducted in 17 countries

*Author for correspondence: <azharulislam@du.ac.bd>. ${ }^{1}$ Counselling Psychologist in Training, University of Dhaka, Dhaka-1000, Bangladesh. 
revealed that 'on average 1 in 20 individual reported having an episode of depression in the previous year(2). Globally more women are affected by depression with a life risk for development of depression $20-25 \%$ while the figure is $7-12 \%$ for men (3). The estimated prevalence of depression in Bangladesh is $3-4 \%$ and the lifetime prevalence of the major depressive disorder is $4.6 \%$ (3).

Given the gravity of the depression among women, clinicians and researchers emphasize exploring its psychosocial and gender-specific determinants ${ }^{(4)}$. Review of the subcontinent's studies revealed 'marriage related issues, domestic violence, verbal or physical abuse by in-laws, stressful life and poor social conditions' as the key factors of women's poor mental health(4). Hence, women empowerment is critical for their health. Participation in the workforce through proper education is, for instance, believed to be crucial determinant for the overall well-being of women. Women's engagement in employment has been interpreted as either positive (role enhancement theory)(5) and negative (role strain theory)(6) to their mental health. Multiple roles at home and workplace are assumed to create role strain as a consequence of role conflict or role overload (6). This, in turn, may reduce the quality of life by experiencing depression, stress, and ill-health. The role enhancement theory, in contrast, argued that the benefit of multiple roles offset the negative consequences expected to elicit from role conflicts, and a net gratification is attained(5). Support for both arguments is found although strong evidence endorses the positive side of multiple roles of women from the psychological perspective ${ }^{(7-9)}$. The partners of employed women are found to be proactive in the household works. This, in turn, increases marital satisfaction. Husband's proactive engagement in household works and high marital satisfaction reduce the level of depression among married women ${ }^{(8)}$.

Marital satisfaction and depression are, however, well-associated ${ }^{(10,11)}$ and could easily influence each other, i.e., poor marital satisfaction may lead to depression or viceversa. This may create a puzzle in prioritizing the most crucial risk factors for depression. A longitudinal study with newly married couples revealed that the causal relationship between these two constructs is sex-specific. That is, for men depression affects marital satisfaction but for women, marital satisfaction affects the level of depression(12). Therefore, attention at marital issues is critical for addressing women's depression.

Based on the review above, employment status, academic qualification, marital satisfaction and psychological well-being emerged as the major predictors of depression among married women in different cultural contexts. In this study, we intended to test to what extent these predictors influence the depression of a sample of Bangladeshi women. We also explored the unique contribution of each of them in explaining their depression. Prevalence of clinical depression among the study sample is also investigated. 


\section{Materials and Methods}

Two hundred married women with mean age of 37.17 years $(S d=8.35)$ were recruited following purposive sampling technique from the Dhaka city. More than half of them were employed (52.5\%). Forty per cent of the total respondents had an academic qualification of post graduation or more while another 30\% studied up to a bachelor (Table 2).

The Bangla depression scale ${ }^{(13)}$ was used to measure depression among participants. The scale consists of 30 items with 5 point rating ranging from 'not at all applicable (1)', 'not applicable (2)', 'uncertain' (3), 'a bit applicable' (4) and 'totally applicable (5). The total score is the sum of all items with a range from 30 to 150. A higher score indicates a higher level of depression. The authors derived 93.5 as the cut-off point for screening depressed individuals. A total score 93.5 or more, therefore, for an individual should be considered as being 'depressed'(13). The scale has been frequently used in psychological research and clinical practice in Bangladesh. Internal consistency of the scale for this sample was excellent (Cronbach's alpha 0.95).

Psychological well-being was measured, using Bangla version ${ }^{(14)}$ of General Health Questionnaire-28 (GHQ-28)(15). The GHQ-28 was designed to detect psychiatric problems among the general population ${ }^{(16)}$. The items of the questionnaire are answered in a fourpoint Likert scale ranging from 0 (above average) to 4 (far below average). The total score is calculated by summing all the items, which gives a range of 0 to 84 . A higher score indicates worst psychological well-being. The GHQ-28 measures four sub-domains of psychological well-being, i.e., somatic symptoms, anxiety and insomnia, social disfunction and severe depression. Psychometric properties of this scale have been tested in numerous studies ${ }^{(16,17)}$. In this study, the Cronbach's alpha was 0.90 .

The Locke Wallace-Marital Adjustment Test (LWMAT) was designed to assess the level of marital satisfaction of couples(18). The total score is the sum of all 15 items, ranging from 2 to 158. A higher score indicates better adjustment with marital life. Due to its brevity and availability, therapists and clinicians are increasingly using the LWMAT. The scale has been tested for its psychometric properties with various sample ${ }^{(18,19)}$. In this study, we used the Bangla version of LWMAT ${ }^{(20)}$. The reliability of the Bangla LWMAT for this sample was found very satisfactory (Cronbach's alpha 0.80, Split-half reliability 0.72). Validity was judged by correlating the Bangla LWMAT with the depression scale $(\mathrm{r}=-0.478, \mathrm{p}<0.0001)$ and the psychological well-being scale as measured by GHQ-28 ( $\mathrm{r}=-0.391, \mathrm{p}<0.0001)$.

Along with psychological measures, participants reported their employment status (employed and unemployed) and academic qualification. Ethical approval was obtained from the concerned authorities prior to the study. Written consent was also taken from each of the participants. Two assistant counselling psychologists conducted the field 
testing after getting proper training on administering scales and handling fatigue of the participants. All three scales were administered at a time.

\section{Results and Discussion}

Data were analyzed, using computer program SPSS version 20. Descriptive statistics is presented for the key variables. Variations among group means were tested, using t-test and ANOVA. The role of predictors (employment and academic status, marital satisfaction, and psychological well-being) on depression was tested using hierarchical multiple regression analysis.

Among the 200 participants, 15\% crossed the cut-point (93.5) of the depression scale with a mean of $106.27(\mathrm{Sd}=9.61)$, which indicates that 15 out of 100 women are likely to be diagnosed as experiencing clinical depression (Table 1 ).

Table 1. Depression score according to cut-point (93.5).

\begin{tabular}{cccccc}
\hline Depression score & $\mathrm{N}$ & $\%$ & Mean $(\mathrm{Sd})$ & Minimum & Maximum \\
\hline$<93.5$ & 170 & 85.0 & $65.65(15.46)$ & 30 & 93 \\
$\geq 93.5$ & 30 & 15.0 & $106.27(9.61)$ & 94 & 125 \\
\hline
\end{tabular}

The depression score of the study sample significantly varied by academic qualifications, $\mathrm{F}(3,196)=5.75, \mathrm{p}=0.001$, with the lowest qualification (up to SSC) scoring highest depression $(\mathrm{M}=84.33, \mathrm{Sd}=18.05)$ than the three other levels. As for employment status, unemployed women reported significantly higher depression $(\mathrm{M}=78.61, \mathrm{Sd}=$ 20.26) than employed sample $(M=65.52, S d=19.12)$. The variations of marital satisfaction remain insignificant within academic and employment categories. The variations of psychological well-being, on the other hand, were significant only for employment categories (Table 2).

In order to explore the role of employment status, marital satisfaction, psychological well-being and academic qualification on depression, hierarchical multiple regression was performed using the enter method. Preliminary analyses were conducted to ensure no violation of the assumptions of normality, linearity, multicollinearity and homoscedasticity. Categorical predictors such as academic qualification and employment status were transformed into dummy variables to fit with the regression analysis ${ }^{(21)}$. For the academic qualification, three dummy variables (SSC, HSC and Bachelor) were created considering 'postgraduate and above' as the reference category (Table 3). As for employment status 'employed' was referenced value. Marital satisfaction and psychological well-being were entered in step 1, dummies of academic qualification in step 2 and dummy of employment status in step 3. 
Marital satisfaction and psychological well-being explained $50.9 \%$ of the variances in the depression score (Step 1). After adding academic qualification in the model (Step 2), the value of $\mathrm{R}^{2}$ increased to 0.548 indicating a $5 \%$ contribution. In the third step, employment was added to the model claiming further $1.6 \%$ increase in the variance of depression score. All $\mathrm{R}^{2}$ changes were significant at 0.0001 level.

Table 2. Mean and Sd of the psychological measures by academic qualification and employment status.

\begin{tabular}{llcccc}
\hline Variable & Attribute & $\begin{array}{c}\text { Frequency } \\
(\%)\end{array}$ & $\begin{array}{c}\text { Depression* } \\
(\text { Mean, Sd) }\end{array}$ & $\begin{array}{c}\text { Marital } \\
\text { Satisfaction } \\
(\text { Mean, Sd) }\end{array}$ & $\begin{array}{c}\text { Psychological }{ }^{* *} \\
\text { Well-being } \\
(\text { Mean, Sd) }\end{array}$ \\
\hline $\begin{array}{l}\text { Academic } \\
\text { qualification }\end{array}$ & Up to SSC & $30(15.0)$ & $84.33(18.05)$ & $109.87(25.07)$ & $\begin{array}{c}26.37 \\
(11.26)\end{array}$ \\
& Up to HSC & $29(14.5)$ & $75.55(19.56)$ & $103.79(27.65)$ & $\begin{array}{c}24.38 \\
(11.24)\end{array}$ \\
& Up to Bachelor & $61(30.5)$ & $68.72(21.62)$ & $104.61(35.26)$ & 22.28 \\
& Postgraduate & $80(40.0)$ & $67.94(19.50)$ & $103.34(29.04)$ & $\begin{array}{c}14.07) \\
(12.24)\end{array}$ \\
& and above & & & & 20.51 \\
$\begin{array}{l}\text { Employment } \\
\text { status }\end{array}$ & Employed & $105(52.5)$ & $65.52(19.12)$ & $107.22(30.76)$ & $(11.73)$ \\
& Unemployed & $95(47.5)$ & $78.61(20.26)$ & $102.06(29.55)$ & 25.24 \\
& & & & $(13.12)$ \\
\hline
\end{tabular}

*The mean differences of depression scores by academic qualifications $(\mathrm{F}=5.75,3,196, \mathrm{p}=0.001)$ and employment status $(t=-4.7, \mathrm{p}=0.0001)$ are significant at the 0.01 level. ${ }^{* *}$ The mean difference of psychological well-being $(t=-2.69, p=0.008)$ is significant at the 0.01 level for the employment category only.

Table 3. Descriptive statistics of the variables used in the multiple regression models.

\begin{tabular}{lcccc}
\hline Variable & Minimum & Maximum & Mean & Sd \\
\hline Depression & 30 & 125 & 71.74 & 20.685 \\
Marital satisfaction & 13 & 158 & 104.77 & 30.228 \\
Psychological well-being & 3 & 63 & 22.76 & 12.603 \\
SSC (Dummy) & 0.00 & 1.00 & 0.1500 & 0.35797 \\
HSC (Dummy) & 0.00 & 1.00 & 0.1450 & 0.35298 \\
Bachelor (Dummy) & 0.00 & 1.00 & 0.3050 & 0.46156 \\
Unemployed (Dummy) & 0.00 & 1.00 & 0.4750 & 0.50063 \\
\hline
\end{tabular}


Examining the unique contribution of each of the predictors in the final model, psychological well-being $(\beta=0.515, \mathrm{p}<0.0001)$ and the marital satisfaction $(\beta=-0.276$, $\mathrm{p}<0.0001)$ appeared to be the most influential predictors. Controlling for the effect of these two, academic qualification was able to predict additional 5\% variances in the depression score (Step 2). Lower education (SSC) was found to have significantly higher depression than the reference category, i.e., postgraduate and above.

Finally, controlling for all above variables, employment status uniquely predicted $1.6 \%$ variances with employed women showing significantly lower depression than their unemployed counterparts (Table 4).

The directions of the relationship between predictors and dependent variable suggested that if a married woman with poorer psychological well-being, lower marital satisfaction, and lower educational qualification is unemployed, she is more likely to be diagnosed as depressed as the opposite (Table 4).

Table 4. Effect of employment and academic status, marital satisfaction and psychological wellbeing on depression.

\begin{tabular}{|c|c|c|c|c|c|c|}
\hline \multirow[t]{2}{*}{ Predictors } & \multicolumn{2}{|c|}{$\begin{array}{c}\text { Unstandardized } \\
\text { coefficients }\end{array}$} & \multirow{2}{*}{$\begin{array}{c}\begin{array}{c}\text { Standardized } \\
\text { coefficients }\end{array} \\
\text { B }\end{array}$} & \multirow[t]{2}{*}{$\mathrm{t}$} & \multirow[t]{2}{*}{$\mathrm{R}^{2}$} & \multirow[t]{2}{*}{$\Delta R^{2}$} \\
\hline & B & SE B & & & & \\
\hline \multicolumn{7}{|l|}{ Step 1} \\
\hline Marital Satisfaction & -1.73 & 0.037 & $-0.253^{*}$ & -4.658 & 0.509 & \\
\hline Psychological Well-being & 0.945 & 0.089 & $0.567^{*}$ & 10.614 & & \\
\hline \multicolumn{7}{|l|}{ Step 2} \\
\hline Marital Satisfaction & -0.195 & 0.036 & $-0.285^{*}$ & -5.452 & 0.548 & $0.050^{*}$ \\
\hline Psychological Well-being & 0.872 & 0.087 & $0.531^{*}$ & 10.075 & & \\
\hline SSC & 13.154 & 3.035 & $0.228^{*}$ & 4.334 & & \\
\hline HSC & 4.920 & 3.029 & 0.084 & 1.625 & & \\
\hline Bachelor & 0.080 & 2.368 & 0.002 & 0.034 & & \\
\hline \multicolumn{7}{|l|}{ Step 3} \\
\hline Marital Satisfaction & -0.189 & 0.035 & $-0.276^{*}$ & -5.357 & 0.562 & $0.016^{*}$ \\
\hline Psychological Well-being & 0.846 & 0.086 & $0.515^{*}$ & 9.865 & & \\
\hline SSC & 10.251 & 3.174 & $0.177^{*}$ & 3.229 & & \\
\hline HSC & 4.178 & 2.994 & 0.071 & 1.396 & & \\
\hline Bachelor & -0.588 & 2.343 & -0.013 & -0.251 & & \\
\hline Unemployment & 5.669 & 2.098 & $-0.137^{* *}$ & 2.702 & & \\
\hline
\end{tabular}

${ }^{*} \mathrm{p}<0.0001,{ }^{* *} \mathrm{p}<0.01 . \mathrm{F}(2,197)=102.08, \mathrm{p}<0.0001$ for step $1 ; \mathrm{F}(3,194)=49.18, \mathrm{p}<0.0001$ for step $2, \mathrm{~F}(1,193)=43.53, \mathrm{p}<0.0001$ for step 3 .

Fifteen per cent of the preesent study participants are found as experiencing clinical depression. This is slightly less than the overall prevalence of psychiatric disorders in Bangladesh $(16.1 \%)^{(22)}$. Both educational and employment status determined the level of 
depression for the participants. Lower education was associated with higher depression. Similarly, unemployed participants reported higher depression than the employed women. These findings supported the role enhancement theory(5). Education and employment bring crucial rewards, such as role-privileges, status security, an opportunity for status enhancement and role performance. This, in turn, foster enriched personality and ego gratification ${ }^{(5)}$ ultimately preventing participating women from falling in depression.

As expected, psychological well-being and marital satisfaction were the most influential determinants of depression. This finding is consistent with existing literature (23-25). Poor psychological well-being is associated with increased symptoms accounted for depression. Additionally, poorer marital satisfaction might hinder healthy interpersonal communication and family process that in turn caused depression. However, since the nature of the study is correlational, the opposite is also possible ${ }^{(25)}$.

Psychological well-being, however, did vary with employment status but not with the academic qualification. Therefore, we can assume that whatever the level of education, a corresponding employment can increase psychological well-being, which in turn might reduce depression.

Interestingly, the variations of marital satisfaction across the educational and employment groups remain insignificant with slightly lower satisfaction reported for the higher education group. It indicates that a happily married woman could experience episodes of depression if she had lower education and a lack of employment.

The findings of this study should be considered with caution, as the sample size was comparatively small and selected purposively, therefore, they lack external validity. The information about the types of job and the year of experience was missing. Both can determine the level of satisfaction as well as the level of depression. Moreover, we did not ask the unemployed group for not having been employed. This might be a vital point as it could be their conscious choice not to work outside. In such a situation there might be other crucial factors playing a role in depression. Future studies should explore these possibilities.

Despite these limitations, the study highlighted some areas associated with clinical practice and research. Married women's depression is the outcome of multiple and coexistential biopsychosocial determinants out of which psychological well-being, marital satisfaction and academic and employment status accounted for more than 50 per cent. Therefore, intervention to address the depression of married women could be beneficial if a holistic approach is adopted prioritizing all these factors.

\section{References}

1. APA 2013. Diagnostic and Statistical Manual of Mental Disorders: DSM-5. Fifty ed. Washington DC: American Psychiatric Association. 
2. Marcus M, MT Yasamy, M van Ommeren and D Chisholm 2012. Depression, a global public health concern. WHO Department of Mental Health and Substance Abuse: 1-8.

3. Firoz A, M Karim and M Alam 2007. Community based multi-centric service oriented research on mental illness with focus on awareness, prevalence, care, acceptance and follow-up in Bangladesh. In: Manual on Mental Health for Primary Health Care Physicians. 2nd ed. NIMH \& WHO.

4. Zahidie A and T Jamali 2013. An overview of the predictors of depression among adult Pakistani women. Journal of the College of Physicians and Surgeons Pakistan 23(8): 574-580.

5. Sieber SD 1974. Toward a theory of role accumulation. American Sociological Review 39(4): 567.

6. Goode WJ 1960. A Theory of Role Strain. American Sociological Review 25(4): 483- 496.

7. Ahrens CJC and CD Ryff 2006. Multiple roles and well-being : Sociodemographic and psychological moderators. Sex Roles 55(11-12): 801-815.

8. Saenz R, WJ Goudy and FO Lorenz 1989. The effects of employment and marital relations on depression among Mexican American women. Journal of Marriage and the Family 51(1): 239-251.

9. Kessler RC and J a McRae 1982. The effect of wives' employment on the mental health of married men and women. American Sociological Review 47(2): 216-227.

10. Zelkowitz P 2004. Factors associated with depression in pregnant immigrant women. Transcultural Psychiatry 41(4): 445-464.

11. Milad G, S Izzeldin, F Tofail, T Ahmed, M Hakim, I Khalil and P Wa 2013. Association between child diarrhea and maternal depression. Journal of Shaheed Suhrawardy Medical College 5(1): 14-20.

12. Fincham F, S Beach, G Harold and L Osborne 1997. Marital satisfaction and depression: Different causal relationships for men and women? Psychological Science 8(5): 351-357.

13. Uddin $Z$ and MM Rahman 2005. Development of a scale of depression for use in Bangladesh. Bangladesh Psychological Studies 15: 25-44.

14. Banu SF 2001. Stress and burden of the caregivers of chronic mental adult patients. M. Phil. thesis, Department of Clinical Psychology, University of Dhaka.

15. Goldberg DP and VF Hillier 1979. A scaled version of the general health questionnaire. Psychological Medicine 9(01): 139-145.

16. Goldberg DP, R Gater, N Sartorius, T Ustun, M Piccinelli, O Gureje and C Rutter 1997. The validity of two versions of the GHQ in the WHO study of mental illness in general health care. Psychological Medicine 27(01): 191-197.

17. Im H, KY Lee and HY Lee 2013. Acculturation stress and mental health among the marriage migrant women in busan, South Korea. Community Mental Health Journal 50: 497-503.

18. Locke HJ and KM Wallace 1959. Short marital-adjustment and prediction tests: Their reliability and validity. Marriage and Family Living 21(3): 251-255.

19. Haque A and B Davenport 2009. The assessment of marital adjustment with muslim populations A reliability study of the Locke-Wallace marital adjustment test. Contemporary Family Therapy 31(2): 160-168. 
20. Deeba F and N Khatun 2012. Reliability and validity of the Bengali marital adjustment test. Uplublished.

21. Field A 2007. Discovering Statistics Using SPSS. SAGE Publications.

22. WHO and MOHFW 2007. WHO-AIMS Report on Mental Health System in Bangladesh: A Report of the Assessment of the Mental Health System in Bangladesh. Dhaka, Bangladesh.

23. Holden KB, MSP Hall, MM Robinson, MS Triplett, D Babalola, V Plummer, H Treadwell and LD Bradford 2012. Psychosocial and sociocultural correlates of depressive symptoms among diverse African American women. Journal of the National Medical Association 104: 493-504.

24. Rich JL, JM Byrne, C Curryer, JE Byles and D Loxton 2013. Prevalence and correlates of depression among Australian women: A systematic literature review, January 1999January 2010. BMC Research Notes 6(1): 424.

25. Amiri S, M Khousheh, F Ranjbar, A Fakhari, A Mohagheghi, A Farnam, S Abdi and A Alizadeh 2012. Factors related to marital satisfaction in women with major depressive disorder. Iranian J. Psychiatry 7(4): 164-169.

(Manuscript received on 15 October, 2015; revised on 22 December, 2015) 